- Examines issues surrounding the use of active anaesthetic gas scavenging systems (AGSS) during relative analgesia

- Confirms the legal position with respect to staff exposure to nitrous oxide and highlights the

- Identifies sources of nitrous oxide pollution and offers practical advice to help reduce

unnecessary exposure of practice staff

\title{
Gone to waste, or something to get your teeth into?
}

\author{
G. Dillow ${ }^{1}$
}

Geoff Dillow, author of Dental compressed air and vacuum systems - 2003, ${ }_{1}^{1}$ a supplement to the NHS Estates publication Health technical memorandum No 2022: Medical gas pipeline systems, ${ }^{2}$ examines issues surrounding the use of scavenging systems for nitrous oxide during relative analgesia (RA) procedures in dentistry. Practical advice to help reduce unnecessary exposure of practice staff is offered.

\section{INTRODUCTION}

There is no intention here to enter into a debate on the possible harmful effects of day to day exposure to low levels of nitrous oxide, ${ }^{3-15}$ or for that matter, into a similar debate on the efficacy of various types of scavenging system. Indeed, this latter debate has been rumbling on for at least 10 years, involving various claims and counter claims of equipment performance. However, and rather worryingly, one of the conclusions reached ${ }^{16}$ during system performance assessments was that, even with an anaesthetic gas scavenging system fitted and performing to specification, there may be times when operatives are exposed to concentrations of nitrous oxide above the recommended limits.

Taking a rather simplistic view, the premise that breathing anything we were not intended to breathe can only be detrimental, provides more than enough reason to reduce our exposure. Analogously, anything we can do that reduces unnecessary exposure to the offending substance must be beneficial.

The purpose of this article is, therefore, to examine the sources of nitrous oxide pollution in a dental operating area and suggest methods by which their effects can be reduced.

${ }^{1}$ Healthcare Technical Training Consultant 51 Inglenook

Close, Crook, County Durham, DL15 8GA

Correspondence to: Mr Geoffrey Dillow

Email:geoff@dillow72.freeserve.co.uk

\section{Refereed Paper}

Received 22.10.03; Accepted 13.07.04

doi: 10.1038/sj.bdj.4812550

๑ British Dental Journal 2005; 199: 9-12

\section{WHAT, IF ANY, ARE THE LEGAL ASPECTS OF EXPOSURE TO NITROUS OXIDE?}

Under the Control Of Substances Hazardous to Health (COSHH) Regulations: $2002^{17,18}$ it is legally incumbent on all organisations using nitrous oxide to control the exposure of staff to this gas in accordance with the assigned current UK Occupational Exposure Standard (OES) of $100 \mathrm{ppm}$ over a time-weighted average period of eight hours. ${ }^{19-21}$

A further legal requirement of the COSHH Regulations is the need to produce a 'suitable and sufficient' risk assessment, in order to identify when and where the nitrous oxide is used and the staff most exposed. To complete such a risk assessment it will be necessary to produce a plan for monitoring the exposure of staff, since measurements of nitrous oxide are needed to determine the type and extent of necessary controls.

Such monitoring should include:

- Leak testing of equipment

- Monitoring of air in the workers' personal breathing zone

- Environmental (room air) monitoring.

Before any such COSHH assessment is carried out, all gas scavenging and room ventilation equipment must be proven to be capable of meeting the performance standards established at commissioning. ${ }^{22-24}$

The risk assessment may show that existing controls and procedures are satisfactory. However, this should not lead to complacency: periodic review will be necessary. The frequency of such reviews will depend on the nature of the risks but in any event, must not be greater than five years. Changes in operating procedures, ventilation, delivery and scavenging equipment, or accommodation will require an immediate reassessment.

When the risk assessment identifies inadequate control measures, improvements must be made in order to comply with COSHH.

\section{WHAT ARE THE SOURCES OF POLLUTION?} a) Gas supplies and the anaesthesia machine

Leakage during administration from the low-pressure anaesthetic delivery system is a common source, due to loosely assembled or deformed conical and threaded connections and defective or worn seals, breathing bags and hoses. Additionally, rubber and plastic components are potential sources of leakage if they have been degraded by reaction with nitrous oxide and/or oxygen, or repeated sterilisation.

Leaks from high-pressure connections like cylinders, terminal units and connecting hoses and the anaesthetic machine regulators and internal pipework are also possible.

\section{b) The gas scavenging system}

Leakage from the scavenging mask can be one of the most significant sources of nitrous oxide exposure because the breathing zones of dentist and assistant are in close proximity to the mask.

\section{c) Work practices}

Relative analgesia provides ample, often difficult to avoid, scope for escape of gas into the operating environment. In particular, working with anxious or difficult 
patients eg children, may cause considerable spillage of gas into the area, albeit the scavenging system is working and connected. Unfortunately, dental work confines operatives closely to an operating site through which gases are exhaled when mouth breathing is taking place.

\section{WHAT MEASURES CAN BE TAKEN TO AVOID EXPOSURE?}

\section{a) The medical gas system and anaesthesia} machine

Regular, well-planned maintenance undertaken by reputable organisations and equipment users pays dividends in terms of equipment performance and leak reduction. User maintenance is particularly important, as it involves daily/pre-use checks on anaesthesia machine operation and on all rubber hoses, connections, tubing, and breathing bags. Damaged or worn components should be replaced as a matter of course, not by 'waiting until the next service visit'.

Technical checks on anaesthetic equipment includes searches for leaks on both high and low pressure connections, although many commercial service organisations do not test the breathing circuit, unless specifically requested to do so. It is important that any service regime offered is to the satisfaction of the operating staff. No service routine should be accepted without question, appreciation or understanding of what will take place. All service visits should be accompanied by a service report detailing the work completed, any recommendations for further action and the name of the person who performed the task. Serviced machines should be left with a label indicating the date of completion of a service and the due date of the next service.

Almost certainly, a service organisation attending an anaesthesia machine will not be responsible for maintaining the associated medical gas system. It is important, therefore, that the requirements listed above are applied equally to the latter company. Leaks from terminal units are a source of pollution that should not be ignored. Statements such as 'Oh, it's been hissing like that for about a month now' (or, in one similar case experienced by the author, for three years!) are neither conducive to good health, nor gas conservation!

Some RA equipment requires on-site connection of high-pressure gas cylinders. A lack of training in their safe storage, handling, connection and disconnection is apparent. Again, ample opportunity for an often-unconsidered source of leakage is presented.

\section{b) Scavenging systems}

Scavenging masks are available in a variety of sizes. Attempts should be made to ensure that the mask is always fitted comfortably and securely to the patient.

The scavenging system should be connected and operational before the nitrous oxide is turned on.

Operation of the scavenging system should be confirmed by using a receiving system that contains a float that rises under flow conditions and is positioned so that it is always visible to the operator. Don't trust the 'on' light on the wall!

Any filter in a receiving system should be cleaned at least once a week.

Regular maintenance of the scavenging system should include a quarterly check of flow rates at each terminal unit and an annual performance check on the complete system.

All scavenging pumps should exhaust via a suitably labelled and constructed terminal, to the outside of the building, away from fresh air intakes, windows, doors, or walkways. Scavenging systems should not exhaust into a recirculating ventilation system. Although not common practice in the UK, BS EN $737-2^{23,24}$ (see below) does allow exhaust into a "non-recirculating' extract ventilation system.

\section{c) Operating area ventilation}

Operating theatre ventilation, equating to about 20 air changes per hour, provides useful removal of waste anaesthetic gases. Used in conjunction with an active scavenging system, low residual concentrations (circa 25 ppm) can be obtained. However, community health centre-based practices and 'mobile' units do not often have the luxury of these facilities. In some areas the use of nitrous oxide without ventilation is (fortunately!) forbidden but the fact remains that in many practices where RA takes place, there is no dedicated scavenging system and certainly no ventilation system with air exchange rates approaching those of an operating theatre. Surprisingly, many older Dental Access Centres also have no scavenging provision. A more modern centre may be provided with a dedicated scavenging system, comprising a remote pump and one or more British (or European) Standard terminal units, and receiving systems.

Local exhaust ventilation systems operating on the principle of capture of waste gases during mouth exhalation have been commercially available for some while. Such equipment usually relies on a relatively high flow of 'capturing' air through the patient's breathing zone and care must be taken to ensure that this flow is not greatly disturbed during the operating procedure. Positioning of capture apparatus is, therefore, particularly important, as impeding intended airflow patterns could cause the waste gases ${ }^{25}$ to be diverted into the operatives' breathing zones. Dedicated equipment of this type has been shown to be highly effective in the removal of waste gases ${ }^{9}$ but is not in common use in dental practices as, by necessity, it is generally placed in close proximity to the patient, can interfere with work practices, can produce high noise levels when operating and attracts additional installation and maintenance costs

If use of nitrous oxide is envisaged in any area, an appropriate risk assessment must be performed, in accordance with COSHH requirements. This process, based on the number of RA procedures conducted each day, may well identify the need to reduce exposure by providing room or local exhaust ventilation in conjunction with a scavenging system.

\section{d) Work practices}

The simple checklist below will help reduce unnecessary exposure:

- Inspect delivery systems and all connections before starting gas administration.

- Make sure that breathing bags, hoses, and clamps are in place before turning on the RA machine.

- Connect the scavenging mask properly to the gas delivery hose and the scavenging system.

- Turn on the nitrous oxide only when the scavenging unit is operational - (Look at the float!) - and the scavenging mask is secured in accordance with the manufacturer's instructions.

- Do not fill any breathing bag (if fitted) to capacity with nitrous oxide as an overinflated bag can cause excessive leakage from the scavenging mask. Collapsing and expanding bag activity shows that appropriate amounts of nitrous oxide and oxygen are being delivered to the patient.

- Flush the system after surgery by administering oxygen to the patient through the RA equipment before disconnecting the gas delivery system. The flushing time will be dependent on the clinical needs of the patient but is usually from two to five minutes.

- Encourage patients to minimise talking and mouth breathing during surgery. When mouth breathing is apparent, avoid the patient's breathing zone as far as is possible.

\section{e) Training}

There is no doubt that training offers the key to solving many of the problems highlighted above and, indeed, below:

- Equipment management and maintenance, medical gas system installation, validation and management, cylinder handling, storage and use, the importance of the correct use of scavenging equipment and working methods aimed at reducing exposure: all are areas requiring attention. 
- Operatives need to be provided with training unfettered by the possibility of 'handed down' bad practice, in order to make the most effective use of systems and equipment.

- All too often the complaint 'Training is too expensive' is voiced. If you agree with this, consider the cost of ignorance!

This would, perhaps, have been a suitable point to conclude this short article, were it not for the fact that during the preparation of the Dental compressed air and vacuum supplement to HTM 2022, other facts arose which the author feels require some clarification. These follow.

\section{CONNECTION OF ANAESTHETIC GAS SCAVENGING SYSTEM RECEIVERS TO DENTAL VACUUM SYSTEMS}

Scavenging systems built to British Standard $6834^{26}$ are designed to operate within a flow rate range of 80 to $130 \mathrm{l} / \mathrm{min}$ AT THE WALL / PENDANT TERMINAL UNIT. When connected to such a terminal, the receiver system (to which the patient-hose connection is made) is designed to produce only a very small negative pressure at the patient connection. The maximum allowable flow generated by this pressure is only $0.5 \mathrm{l} / \mathrm{min}$ at the patient connection.

The European Standard BS EN 737-2 prescribes a system flow range of 25 to 50 $1 /$ min and a consequent maximum flow from the patient connection of $0.05 \mathrm{l} / \mathrm{min}$.

These flows cannot be detected by placing one's hand across the patient connection port on the receiver. The appearance is, therefore, of a unit that is not working. However, the whole BS 6834 (and EN 7372) design philosophy is that negative pressure should not be applied to the patient; rather the patient (or a ventilator connected to the patient) expires into what is essentially an 'open space' (ie the receiver), The receiver, therefore, is designed to produce zero back pressure (positive) and very little negative pressure and is an essential safety element in the scavenging system.

Returning now to the situation where chairside vacuum is attached to either British or European Standard receivers. MID and HIGH volume vacuum systems, as defined in BS EN ISO 10637:2000, ${ }^{27}$ generate a flows $90 \mathrm{l} / \mathrm{min}$ about $300 \mathrm{l} / \mathrm{min}$. Therefore, once the upper limits of $501 / \mathrm{min}$ (BS EN 737-2) or 130 1/min (BS 6834) are exceeded, a higher than intended flow may be generated at the receiver patient-hose connection port and may possibly be detected by hand. This is often perceived as 'proof' that the system is working properly. It is, however, likely that these flows are in excess of those prescribed in the Standards and excess negative pressures could be applied to the patient mask.
A typical nasal mask for use with British or European Standard scavenging systems comprises inner and, slightly larger, outer mask components. The inner mask has connections that supply anaesthetic gas to the patient. Usually a relief valve is attached to the inner mask to release excess gas into the outer mask. The outer mask is connected to the scavenging system, both to capture waste gases from the patient and any excess gas supplied to the patient by the RA equipment. The waste gas is, therefore, simply driven into the scavenging system by the expiration efforts of the patient and excess flow from the RA machine.

This type of mask will protect the patient against excess negative pressures only if pressure in the scavenging system is insufficient to operate the internal relief valve, or the valve is of a type which allows excess vacuum to be counterbalanced by inlet of atmospheric air.

The latter type of valve is to be found in masks designed for use where an actual flow of air through the outer mask is generated by the scavenging system. It has been determined that a flow of $45 \mathrm{l} / \mathrm{min}$ through the outer mask optimises capture of gases and minimises noise arising from the airflow. ${ }^{28}$

Frequently used in America, these masks are 'powered', (usually) from a dedicated scavenging system but, in some instances, from the dental vacuum system. It is important to note that these systems have NO RECEIVER (Air-break) interposed between the scavenging system terminal and the patient mask. An adjustable flow controller ensures that the mask is effectively scavenged.

Unfortunately, this type of mask will be of little or no use when attached to a British or European Standard system, as the lower edge of the mask is usually provided with slits, which not only prevent inadvertent application of system vacuum to the patient but also serve to help scavenge mouth-breathed gases. Used on British or European Standard systems, exhaled air would simply pass through the slits into the operating area, as there would be little or no airflow through the mask to remove it

The mask would of course work "correctly' if attached to any dental vacuum system generating sufficient flow but it must be remembered that UK dental vacuum systems are not specifically designed for scavenging use; any such connection would require additional equipment to limit flow through the mask to $45 \mathrm{l} / \mathrm{min}$ and prevent inadvertent application of vacuum to the patient, and/or excessive noise.

Similar flow control equipment would also be needed to connect such a mask DIRECTLY to a terminal unit of either a
British or European Standard scavenging system, as these systems are designed and commissioned to work only with dedicated receiver units. Direct connection of equipment other than a specified receiver is strongly deprecated, as it may well cause ineffective operation of the whole system, resulting in spillage of waste gases into other operating areas.

The morals of this tale are simple: any mask or receiving system should be matched to the scavenging system and, regardless of mask or scavenging system type, the better the fit of the mask, the less will be the overspill of gases.

One final important point is that if, after all this advice to the contrary, the dental vacuum is being used as a scavenging medium, all of the system's 'good work' is wasted if it exhausts into the operating area!

Care should be taken to ensure that ALL scavenging systems exhaust to the outside of the building, ideally via a terminal protected with a wire mesh to prevent ingress of vermin, turned down to prevent ingress of rain and labelled as an 'ANAESTHETIC GAS SYSTEM EXHAUST - NoXIOUS AND FLAMMABLE VAPOURS - KEEP AWAY'. (The 'flammable vapours' is a bit of poetic licence (see below) but it serves to ward off a potential saboteur!)

\section{INTERCHANGE OF EUROPEAN AND BRITISH STANDARD AGSS RECEIVERS}

Operatives should be aware that European (BS EN 737-2) scavenging systems are provided with terminal units (wall or pendant connection points) that are dimensionally different from those on a British Standard (BS6834) system.

European (BS EN 737-2) receivers are, with increasing frequency, being supplied with new anaesthetic equipment (to BS EN 740 ${ }^{29}$ and often become mysteriously 'adapted' to fit the British (BS 6834) systems. This process usually involves removal of the dedicated European Standard interconnecting-hose probe and its replacement by a British Standard probe. Such malpractice is also to be strongly deprecated. The physical differences in terminal unit and associated connecting hose probes are specifically intended to prevent this interchange of receivers.

It is obvious that higher than normal negative pressures could again be generated and experience also shows that BS EN 737-2 receiver used on a BS 6834 system can generate an extremely annoying noise - definitely a 'give away' factor.

\section{To summarise:}

- Absence of an obvious 'draught' into a scavenger receiver port is no indication of system failure or poor performance. 
- A true measure of system performance can only be ascertained by proper quantitative testing.

- Pre-operative observation of receiver float movement, as an indication of system function, should be the norm.

- BS EN 737-2 receivers and connecting hoses must not be 'modified' to work on BS6834 systems and neither system's components should be connected to dental vacuum systems.

- If dental vacuum is used to effect scavenging, using an 'American-type' directly connected facemask, the pump must exhaust outdoors and the flow through the actively scavenged mask must be properly controlled to $45 \mathrm{l} / \mathrm{min}$.

- ALL scavenging systems should exhaust outdoors, either via a suitably labelled and constructed termination point, or the external disposal duct of a non-recirculating ventilation system.

- Masks and receivers should be matched to their respective scavenging systems.

- Actively scavenged masks must not be attached directly to BS 6834 or BS EN 737-2 terminal units.

- Operatives must be trained in the selection and use of scavenging equipment.

\section{Dental vacuum systems and explosion risk}

Given that dental vacuum systems are often fulfilling the role of a scavenging system, the question arises of risk of explosion when system components, in particular electrically powered pumps, are exposed to the waste anaesthetic gases.

In the days when flammable anaesthetic agents were in use it was not unknown for fires or explosions to result from ignition of a mixture of the vaporised anaesthetic agent with air or oxygen. And it was not just flammable liquids used in vaporisers that caused problems: the liquefied petroleum gas cyclopropane proved to be a major explosion risk. The latter is no longer in use as an anaesthetic agent, and other liquid agents used are not considered flammable in normal usage.

Special precautions, involving provision of anti-static materials (including special theatre floor composites) and positioning of electrical sockets and equipment is required whenever flammable agents are considered for use. ${ }^{30-32}$ Active scavenging systems were used to exhaust flammable vapours and gases but care was taken to ensure that all electrical supplies and components were isolated from the exhaust gas stream. Additionally, warning notices were placed near external exhaust terminals to warn of the possibly flammable vapours exuding therefrom (See note on poetic licence above.) The flow of air through the system was much higher than the flow of air expired from the patient. Consequently, considerable dilution of the flammable vapours occurred, to the point where it was unlikely that the concentration of flammable gases in the exhausted mixture would ever reach explosive limits.

Unfortunately, this was not the case with older 'passive' systems, where the driving force for the exhaust gases often came directly from the patient. In at least one instance a fire in the scavenging system resulted from ignition of vapours exuding from the external wall exhaust terminal.

Relative analgesia does not involve the use of flammable anaesthetics and, fortunately, nitrous oxide and oxygen are not flammable gases. These gases, therefore, do not constitute an explosion risk when exhausted through either dental (chairside) vacuum, or scavenging system pumps. Indeed, the structure of most dental vacuum system pumps is exactly similar to those used to power active scavenging systems. Also, the generally higher flow rate used in dental vacuum systems gives an even greater dilution of the waste gas mixture.

There is, however, a side issue, as although nitrous oxide and oxygen are not flammable they are both extremely good supporters of combustion.

In 1999 a nurse received burns when barrier cream from her hands contaminated a high-pressure cylinder connection, subsequently causing a serious fire and explosion when the cylinder valve was opened. ${ }^{33}$ Department of Health advice has also been issued concerning fires arising from lack of maintenance of low-pressure oxygen hoses. ${ }^{34}$

These incidents serve to highlight not only the fact that oxygen and nitrous oxide have the capacity to cause serious fires but also that the lack of training of operatives in the basic principles of cylinder safety is giving rise to unnecessary risks.

A further article will address these issues.

1. Dental compressed air and vacuum systemsSupplement to 2 .

2. HMSO. Health Technical Memorandum No 2022. Medical gas pipeline systems; Volumes 1 and 2; Dental supplement;Ambulance supplement 2003.

3. Fink B R, Shepard TH, Blandau R J. Teratogenic activity of nitrous oxide. Nature 1967; 214: 146-148.

4. Knill-Jones R P, Rodrigues LV, Moir D D, Spence A A. Anaesthetic practice and pregnancy: Controlled survey of women anaesthetists in the United Kingdom. Lancet 1972; 1: 1326-1328.

5. Knill-Jones R P, Newman B J, Spence A A. Anaesthetic practice and pregnancy: Controlled survey of male anaesthetists in the United Kingdom. Lancet 1975;2: 807-809.

6. American Society of Anesthesiologists. Occupational disease among operating room personnel. A national study. Report of an ad hoc committee on the effect of trace anesthetics on the health of operating room personnel. Anesthesiology 1974; 41: 321-340.

7. Bruce D L, Bach M J, Arbit J. Trace anesthetic effects on perceptual, cognitive, and motor skills. Anesthesiology 1974; 40: 453-458.

8. Smith $G$, Shirley A W. A review of the effects of trace concentrations of anaesthetics on performance. $\mathrm{Br}$ Anaesth 1978:50: 701-712.

9. Tomlin PJ. Health problems of anaesthetists and their families in the West Midlands. Br M Journal 1979; 1: 779-784.
10. Cohen E N, Brown B W, Wu M L., Whitcher CE, Brodsky J B, Gift H C, Greenfield W, Jones TW, Driscoll E J. Occupational disease in dentistry and chronic exposure to trace anesthetic gases. J Am Dent Assoc 1980; 101 : 21-31.

11. Axelsson G, Rylander R. Exposure to anaesthetic gases and spontaneous abortion: Response bias in a postal questionnaire study. Int J Epidemio/ 1982; 11: 250-256.

12. Sweeney B, Bingham R M, Amos R J, Petty A C, Cole PV. Toxicity of bone marrow in dentists exposed to nitrous oxide. Br Med J (Clin Res Ed) 1985; 291: 567-569.

13. Henry R J, Jerrell R G. Ambient nitrous oxide levels during pediatric sedations. Pediatr Dent 1990; 12: 87-91.

14. McGlothlin J D, Jensen P A, Fischbach TJ, Hughes R T, Jones $\mathrm{J}$ H. Control of anesthetic gases in dental operatories. Scand J Work Environ Health 1992; 18 Suppl 2:103-105.

15. Rowland A S, Baird D D, Weinberg CR, Shore D L, Shy C $M$, Wilcox $A J$. Reduced fertility among women employed as dental assistants exposed to high levels of nitrous oxide. NEng/ J Med 1992; 327: 993-997.

16. National Institute for Occupational Safety and Health. Control of nitrous oxide in dental operatories.

Cincinnati: Department of Health and Human Services. Public Health Service. Centers for Disease Control and Prevention. National Institute for Occupational Safety and Health. Publication no. DHHS (NIOSH) 94-129.

17. HMSO. The control of substances hazardous to health (COSHH) Regulations 2002.

18. HMSO Approved Code of Practice and Guidance L5 ( $4^{\text {th }}$ ed). 2002.

19. EH40 - Environmental Hygiene $40 / 95$ updated to $\mathrm{EH} 40 / 02$ and amended with a supplement in April 2003; Occupational exposure limits, issued by the Health and Safety Executive. TSO

20. EL(96)33-Occupational exposurestandards for anaesthetic agents. A 'Dear Colleague' letter issued from the NHS Executive Headquarters to NHS Trust Chief Executives and FHSA General Managers on behalf of General Dental Practitioners, March 1996.

21. Advice on the implementation of the health and safety commission's occupational exposure standards for anaesthetic agents - issued by the NHS Executive to NHS Trust Chief Executives and FHSA General Managers, March 1996.

22. Health Technical Memorandum 2025 - Ventilation in healthcare premises. NHS Estates TSO, 1994 (Under revision).

23. BSEN 737- 2: 1998 - Part 2: Anaesthetic gas scavenging systems - basic requirements.

24. BSEN 737-4:1998 - Part 4: Terminal units for anaesthetic gas scavenging systems. British Standards Institution

25. Privately commissioned report No 10865/1 December 1992, Evaluation of the performance of a local exhaust scavenging unit. Building Services Research Association (Not on public release).

26. BS 6834: 1987. Specification for active anaesthetic gas scavenging systems. British Standards Institution

27. BS EN ISO 10637: 2000, Dental equipment. High and medium volume suction systems. British Standards Institution.

28. National Institute for Occupational Safety and Health 1994. Control of nitrous oxide in dental operatories. Cincinnati, OH: U.S. Department of Health and Human Services. Public Health Service. Centers for Disease Control and Prevention. National Institute for Occupational Safety and Health. DHHS (NIOSH) Publication No. 94-129.

29. BS EN 740: 1999 BS 5724-2.204: 1999 Anaesthetic workstations and their modules - Particular requirements. British Standards Institution

30. Health Technical Memoranda - HTM 1 - Anti-static precautions: rubber, plastics and fabrics.

31. HTM 2-Antistatic precautions:flooring in anaesthetising areas.

32. NHS Estates Health Guidance Note. Static discharges TSO - Replaces 30. and 31.

33. Safety Notice: SN 2000(07) Medical gas cylinders-Risk of fire. Issued by UK Medical Devices Agency (Now, with Medicines Control Agency, the Medicines and Healthcare products Regulatory Agency (MHRA)).

34. Medical Device Alert MDA 2003/007 Oxygen Hose Fires - March 2003. (Advice issued by the Medical Devices Agency concerning fires arising from lack of maintenance of low-pressure oxygen hoses). All SN and MDA publications are to be found on the MHRA website at www.mhra.gsi.gov.uk. 